\title{
PENERAPAN CROSSOVER PADA PERILAKU LEBAH SCOUT DALAM ALGORITMA ARTIFICIAL BEE COLONY UNTUK OPTIMASI VEHICLE ROUTING PROBLEM
}

\author{
I Made Widiartha' ${ }^{1)}$ Ngurah Agus Sanjaya ER ${ }^{2)}$ I Wayan Santiyasa ${ }^{3)}$ \\ Program Studi Teknik Informatika, Jurusan Ilmu Komputer ${ }^{1 \text { 2) 3) }}$ \\ Fakultas Matematika dan Ilmu Pengetahuan Alam, Universitas Udayana ${ }^{12}$ 2) 3) \\ madewidiartha@unud.ac.id ${ }^{1)}$ agus.sanjaya@cs.unud.ac.id ${ }^{2}$ santiyasa@cs.unud.ac.id ${ }^{3)}$
}

\begin{abstract}
The economy in Indonesia has shown a relatively consistent increase from year to year where the growth rate at the end of 2017 is 5.5\%. In terms of the trade balance, according to the Indonesian Central Bureau of Statistics (BPS) on January 15, 2018 it was said that Indonesia's trade balance had a surplus of 11.84 billion US dollars. The development of the trade sector in Indonesia is also inseparable from the distribution of goods. The distribution of goods is closely related to the distribution cost factor, because the longer the distribution distance, the longer the time and the greater the operational costs needed to distribute the goods. Therefore, it is necessary to determine the optimal distribution channel to obtain distribution efficiency. The problem of distributing this item to the world of computer science is known as the Vehicle Routing Problem (VRP). Along with the rapid development of technology and information, with the use of technology, research related to the distribution of goods has also been carried out. One method that has superior ability in determining the distribution route is artificial bee colony (ABC). Although it has superior performance, the $A B C$ algorithm still has weaknesses where $A B C$ requires a relatively long time to get an optimum solution. The main cause of this weakness is the bee scout technique in finding solutions (food sources). Looking at the weaknesses of the characteristics of bee scout in ABC, in this study the ABC algorithm was optimized by applying two crossover methods, namely Partially Mapped Crossover and Cycle Crossover on the solution search pattern by bee scout. Crossover is one of the optimization techniques aimed at finding the optimum solution in AG. This is the basis for the implementation of hybrid crossover in this vehicle routing problem. From the results of the study it was found that Cycle Crossover (CX) has a better performance than Partially Mapped Crossover $(P M X)$ in optimizing the ABC algorithm, this can be seen from the CX solution produced for all datasets better than PMX. Besides having a better performance in terms of distance, CX also has a faster time performance than PMX.
\end{abstract}

Keywords: artificial bee colony, vehicle routing problem, crossover

\begin{abstract}
ABSTRAK
Perekonomian di Indonesia telah menunjukkan adanya peningkatan yang relatif konsisten dari tahun ke tahun dimana angka pertumbuhan pada penghujung tahun 2017 adalah 5,5\%. Dari sisi neraca perdagangan, menurut Badan Pusat Statistik (BPS) Indonesia pada tanggal 15 Januari 2018 dikatakan bahwa Neraca Perdagangan Indonesia mengalami surplus sebesar 11,84 milliar dolar AS. Perkembangan sektor perdagangan di Indonesia juga tidak terlepas dari faktor pendistribusian barang. Pendistribusian barang memiliki kaitan yang erat dengan faktor biaya distribusi, karena semakin jauh jarak pendistribusiannya maka semakin lama waktu dan semakin besar biaya operasional yang diperlukan dalam mendistribusikan barang tersebut. Maka dari itu, diperlukan penentuan jalur distribusi yang optimal untuk mendapatkan efisiensi pendistribusian. Permasalahan pendistribusian barang ini pada dunia ilmu komputer dikenal sebagai Vehicle Routing Problem (VRP). Seiring berkembangnya teknologi dan informasi yang pesat, dengan pemanfaatan teknologi, penelitian yang berkaitan dengan pendistribusian barang ini juga telah dilakukan. Salah satu metode yang memiliki kemampuan unggul dalam menentukan rute distribusi adalah artificial bee colony $(\mathrm{ABC})$. Meski memiliki performa yang unggul, tetapi dalam algoritma $\mathrm{ABC}$ masih memiliki kelemahan dimana $\mathrm{ABC}$ membutuhkan waktu yang relatif lama untuk mendapatkan sebuah solusi optimum. Penyebab utama yang menyebabkan kelemahan ini adalah teknik lebah scout dalam mencari solusi (sumber makanan). Melihat kelemahan karakteristik lebah scout dalam ABC maka dalam penelitian ini dilakukan optimasi algoritma $\mathrm{ABC}$ dengan menerapkan dua metode crossover
\end{abstract}


yaitu Partially Mapped Crossover dan Cycle Crossover pada pola pencarian solusi oleh lebah scout. Crossover merupakan salah satu teknik optimasi yang ditujukan untuk pencarian solusi optimum dalam AG. Hal ini menjadi dasar untuk penerapan hybrid crossover dalam permasalahan vehicle routing problem ini. Dari hasil penelitian didapatkan bahwa Cycle Crossover (CX) memiliki kinerja yang lebih baik daripada Partially Mapped Crossover (PMX) dalam mengoptimasi algoritma ABC, hal ini terlihat dari solusi CX yang dihasilkan untuk semua dataset lebih baik dari PMX. Selain memiliki kinerja yang lebih baik dalam hal jarak, CX juga memiliki kinerja waktu yang lebih cepat daripada PMX.

Kata Kunci: artificial bee colony, vehicle routing problem, crossover

\section{PENDAHULUAN}

Perekonomian di Indonesia telah menunjukkan adanya peningkatan yang relatif konsisten dari tahun ke tahun dimana angka pertumbuhan pada penghujung tahun 2017 adalah 5,5 \%. Dari sisi neraca perdagangan, menurut Badan Pusat Statistik Indonesia yang dikemukakan pada tanggal 15 Januari 2018 lalu dikatakan bahwa Neraca Perdagangan Indonesia mengalami surplus sebesar 11,84 milliar dolar AS. Perkembangan sektor perdagangan di Indonesia juga tidak terlepas dari faktor pendistribusian barang. Pendistribusian barang memiliki kaitan yang erat dengan faktor biaya dalam melakukan pendistribusian barang dengan rute yang telah ditentukan, karena semakin jauh jarak pendistribusiannya maka akan semakin lama waktu yang diperlukan dalam mendistribusikan barang, serta semakin besar biaya operasional yang diperlukan dalam mendistribusikan barang tersebut. Maka dari itu, diperlukan penentuan jalur distribusi yang optimal agar dapat melakukan pendistribusian barang yang efisien.

Adapun peningkatan efisiensi dari pendistribusian barang yang dilakukan dapat berupa meminimalisir biaya transportasi serta menghemat waktu dengan mencari jalur atau rute yang terbaik yang meminimalkan jarak serta waktu tempuh. Permasalahan pendistribusian barang untuk mengoptimasi penentuan rute dengan keterbatasan jumlah kendaraan ini disebut juga dengan Vehicle Routing Problem (VRP). Vehicle Routing Problem (VRP) merupakan sebuah permasalahan dalam menentukan rute ketika terdapat beberapa rute yang harus dilalui oleh sejumlah kendaraan dari suatu depot menuju ke beberapa tempat tujuan yang telah ditentukan (agen atau pelanggan) yang tersebar dan dengan biaya termurah yang kemudian berakhir pada depot yang sama.

Seiring berkembangnya teknologi dan informasi yang pesat, dengan pemanfaatan teknologi, penelitian yang berkaitan dengan Vehicle Routing Problem ini juga telah dilakukan. Penelitian sebelumnya dilakukan oleh Shima Sabet et al pada tahun 2016 dengan membandingkan algoritma seperti algoritma genetika, ant colony optimization, particle swarm optimization dan artificial bee colony. Pada penelitian tersebut didapatkan bahwa algoritma artificial bee colony memiliki hasil yang lebih baik dibandingkan algoritma swarm intelligence lainnya [4]. Artificial Bee Colony (ABC) merupakan suatu metode yang mengadopsi perilaku mencari makan (foraging behavior) dari koloni lebah madu. Meski memiliki performa yang unggul, tetapi dalam algoritma $\mathrm{ABC}$ masih memiliki kelemahan dimana $\mathrm{ABC}$ membutuhkan waktu yang relatif lama untuk mendapatkan sebuah solusi optimum [5]. Penyebab utama yang menyebabkan kelemahan ini adalah teknik lebah scout dalam mencari solusi (sumber makanan).

Melihat kelemahan karakteristik lebah scout dalam ABC maka dalam penelitian ini akan dilakukan optimasi algoritma $\mathrm{ABC}$ dengan menerapkan metode hybrid crossover yaitu Partially Mapped Crossover dan Cycle Crossover pada pola pencarian solusi oleh lebah scout. Crossover merupakan salah satu teknik optimasi yang ditujukan untuk pencarian solusi optimum dalam AG. Hal ini menjadi dasar untuk penerapan hybrid crossover dalam permasalahan vehicle routing problem ini dengan harapan hasil yang didapat lebih baik dari algoritma artificial bee colony. Sehingga hasil dari penelitian ini dapat digunakan sebagai solusi untuk pihak pengusaha dalam menentukan rute optimal dalam pendistribusian barang. Rute yang optimal akan menekan biaya operasional dan biaya transportasi yang otomatis akan memperbesar margin profit perusahaan. 


\section{LANDASAN TEORI}

\section{Vehicle Routing Problem}

Vehicle Routing Problem (VRP) adalah merupakan sebuah permasalahan dalam menentukan rute ketika terdapat beberapa rute yang harus dilalui oleh sejumlah kendaraan dari suatu depot menuju ke beberapa tempat tujuan yang telah ditentukan (agen atau pelanggan) yang tersebar dan dengan biaya termurah yang kemudian berakhir pada depot yang sama.

$$
\text { Vehicle Routing Problem }
$$

diklasifikasikan sebagai NP-hard problem, maka dari itu dalam mencari solusi yang feasible tidak dapat menggunakan metode exact optimization namun menggunakan metode heuristic dan metaheuristic [3].

Permasalahan VRP biasanya digambarkan dalam graph yang terdiri dari vertex dan edge. Graph tersebut memetakan permasalahan yang terjadi seperti posisi dari depot yang menjadi titik awal dan titik akhir pendistribusian barang serta penyebaran konsumen yang dilayani. Titik penyebaran dari konsumen dan depot biasanya dilambangkan dengan Vertex $\mathrm{V}_{0}, \ldots, \mathrm{V}_{\mathrm{n}}$ dimana vertex $\mathrm{V}_{0}$ merupakan depot dan vertex lainnya menunjukkan konsumen dengan jumlah $n$. Sedangkan edge menunjukkan waktu, jarak, maupun biaya perjalanan dari satu titik ke titik lainnya. Dalam pencarian solusi, solusi akan dianggap layak apabila dapat memenuhi beberapa syarat diantaranya rute yang terbentuk harus dapat melayani semua konsumen, semua konsumen hanya bisa dikunjungi satu kali, dan semua rute harus dimulai dan selesai di depot.

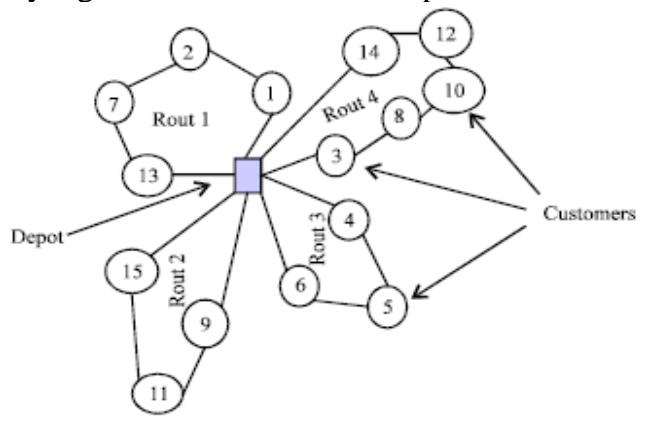

Gambar 1. Ilustrasi graph dalam VRP

Vehicle Routing Problem (VRP) memiliki beberapa varian tergantung pada karakteristik permasalahan yang dihadapi. Salah satu permasalahan VRP tersebut adalah Capacitated Vehicle Routing Problem (CVRP).

\section{Capacitated Vehicle Routing Problem}

Capacitated Vehicle Routing Problem (CVRP) merupakan sekelompok $\mathrm{n}$ pelanggan yang dilayani dari depot 0 , untuk $\mathrm{q}_{\mathrm{i}}$ non negatif, permintaan pelanggan dengan $\mathrm{N}$ kendaraan memiliki kapasitas Q dan jarak atau biaya yakni $\mathrm{C}_{\mathrm{ij}}$ diantara 2 node dari i dan $\mathrm{j}$ dengan kendaraan $\mathrm{k}$ [1]. Sasaran dari permasalahan CVRP penentuan rute optimum dalam pendistribusian barang dengan aturan sebagai berikut :

1. Setiap cabang hanya dikunjungi sekali dalam satu jalur pendisribusian barang dan kembali ke titik awal.

2. Setiap kendaraan yang digunakan dalam pendistribusian barang berawal dan berakhir di depot

3. Total jarak dari setiap rute tidak boleh melewati pembatas.

4. Total permintaan pelanggan dari rute apapun tidak boleh melebihi kapasitas kendaraan.

Adapun model matematika dari CVRP telah diformulasikan oleh Bodin et al adalah sebagai berikut :

$$
\begin{aligned}
& \operatorname{Min} \sum_{k=1}^{N} \sum_{k=1}^{N} \sum_{k=1}^{N} C_{i j}^{k} X_{i j}^{k} \ldots \ldots \ldots \ldots \ldots \ldots \ldots \ldots \ldots \ldots \ldots \ldots \ldots \\
& \sum_{k=1}^{N} \sum_{i=0}^{n} X_{i j}^{k}=1, j=1,2, \ldots, n \ldots \ldots \ldots \ldots \ldots \ldots \ldots \\
& \sum_{k=1}^{N} \sum_{j=0}^{n} X_{i j}^{k}=1, j=1,2, \ldots, n \ldots \ldots \ldots \ldots \ldots \ldots \ldots \\
& \sum_{i=0}^{n} X_{i t}^{k}-\sum_{j=0}^{n} X_{i j}^{k}=0, k=1,2, \ldots, N ; t=1,2, \ldots, n
\end{aligned}
$$

Persamaan 2 dan 3 adalah batasan untuk memastikan bahwa kendaraan yang ada dikunjungi hanya sekali. Kendaraan yang mengunjungi 2 pelanggan akan memberikan nilai 1 atau 0 terhadap $X_{i j}^{k}$ Sedangkan batasan pada persamaan 4 berfungsi untuk 
memastikan kendaraan harus mengunjungi pelanggan secara kontinu.

\section{Partially Mapped Crossover}

Metode Partially Mapped Crossover merupakan salah satu varian metode crossover yang mewariskan sebagian gen orang tua secara searah dan sebagian lainnya secara menyilang kepada kedua anaknya. Pewarisan menyilang ini dilakukan dengan menggunakan posisi-posisi gen kedua orang tuanya yang memiliki nilai yang sama untuk dilakukan pemetaan (mapping). Oleh sebab pewarisan yang menggunakan pemetaan hanya dilakukan pada sebagian gen maka metode ini disebut Partially Mapped Crossover (PMX). Adapun algoritma dari PMX adalah sebagai berikut [2]:

1. Pilih segmen kromosom dari kedua orang tua secara acak dengan cara membangkitkan dua titik (TP1 dan TP2)

2. Salin segmen orang tua 1 ke anak 1

3. Mulai dari posisi TP1lakukan pemetaan gen-gen yang ada di segmen orang tua 2 tetapi tidak ada di segmen orang tua 1.

4. Wariskan setiap gen tersebut ke anak 1 pada posisi hasil pemetaan

5. Setelah semua gen di dalam segmen sudah diwariskan ke anak 1, maka posisi-posisi gen anak 1 yang masih kosong diisi dengan gen-gen orang tua 2 pada posisi bersesuaian

6. Lakukan hal yang sama untuk membangkitkan anak 2 .

\section{Cycle Crossover}

Pada cycle crossover (CX), anak dihasilkan melalui pencarian siklus-siklus (cycle) yang ada pada kedua kromosom orang tua dan mewariskan cycles tersebut secara menyilang dan berarah secara bergantian. Hal ini berarti bahwa pada cycle pertama pewarisan dilakukan secara menyilang, pada cycle kedua pewarisan dilakukan secara searah, cycle ketiga kembali dilakukan secara menyilang, dan seterusnya. Dengan cara ini akan didapat 2 anak yang selalu valid. Adapun algoritma dari CX adalah sebagai berikut [2]:

1. Cari cycle pada orang tua 1 dengan cara :

a. Mulai dari posisi pertama dari orang tua yang belum diwariskan

b. Buat panah ke posisi yang sama pada orang tua 2

c. Buat panah ke posisi gen yang bernilai sama pada orang tua 1

d. Tambahkan gen ini ke cycle

e. Ulangi langkah b sampai dengan d, sampai panah kembali ke posisi awal

2. Wariskan gen-gen orang tua yang berada pada cycle ini kepada kedua anaknya sesuai dengan posisinya dengan cara menyilang, searah, menyilang, searah, dan seterusya.

\section{METODOLOGI PENELITIAN}

Data penelitian yang digunakan merupakan dataset uji yang dibuat oleh Augerat et al (1995). Adapun dataset ini berisikan data jumlah dari vertex yang pada kasus ini dianggap sebagai pelanggan, koordinat dari graph yang akan diuji, jumlah demand/permintaan dari pelanggan, jumlah kendaraan dan kapasitas dari kendaraan tersebut. Adapun dataset uji yang akan digunakan adalah seperti pada Tabel 1 .

Pada Tabel 1. tersebut, dataset yang digunakan bervariasi dalam jumlah pelanggan, jumlah kendaraan serta kapasitas kendaraan yang digunakan. Seperti pada Tabel 1, dapat diketahui bahwa dataset An32-k5 memiliki 32 demand serta verteks yang terdiri dari 1 depot dan 31 pelanggan dimana vertex dengan nomor urut 1 merupakan depotnya (titik awal). Dataset ini memiliki 5 kendaraan dimana jumlah kapasitas kendaraan yang dimiliki adalah 100. 
Tabel 1. Tabel Data Penelitian

\begin{tabular}{|c|c|c|c|}
\hline Yf & $\begin{array}{c}\text { Jumlah } \\
\text { Pelanggan }\end{array}$ & $\begin{array}{c}\text { Kapasitas } \\
\text { Kendaraan }\end{array}$ & $\begin{array}{c}\text { Jumlah } \\
\text { Kendaraan }\end{array}$ \\
\hline A-n32-k5 & 31 & 100 & 5 \\
\hline A-n33-k5 & 32 & 100 & 5 \\
\hline B-n41-k6 & 40 & 100 & 6 \\
\hline B-n44-k7 & 43 & 100 & 7 \\
\hline A-n53-k7 & 52 & 100 & 7 \\
\hline A-n55-k9 & 54 & 100 & 9 \\
\hline
\end{tabular}

Pada tahapan ini, dilakukan perancangan alur proses/logika penyelesaian masalah. Penggambaran proses yang ada dipaparkan menggunakan flowchart. Flowchart ini menggambarkan alur dari sistem dalam penerapan metode crossover dalam Artificial Bee Colony pada Capacitated Vehicle Routing Problem. Dua metode crossover diterapkan untuk memodifikasi karakteristik lebah scout (penjelajah) dalam mencari suatu solusi.

Hasil yang diharapkan dari sistem adalah menampilkan solusi optimum untuk setiap kendaraan menggunakan kolaborasi metode crossover dan ABC. Pada Gambar 1 menampilkan proses dari algoritma ini. Pada proses algoritma Hybrid Crossover-based Artificial Bee Colony (HCABC) seperti yang ditunjukkan pada Gambar 1, solusi awal yang terbentuk akan berjumlah sama dengan jumlah employed bee. Ketika solusi awal telah terbentuk, selanjutnya onlooker bee akan berperan sebagai fungsi objektif untuk memilih employed bee dengan solusi terbaik. Dari solusi terbaik yang telah ditentukan, onlooker bee akan melakukan proses perekrutan soldier (employed bee) yang akan ditugaskan pada setiap scout bee.

Selanjutnya, penerapan metode crossover akan dilakukan oleh scout bee. Metode Crossover yang dilakukan dengan menggunakan crossover yaitu Cycle Crossover (CX) dan Partially Mapped Crossover (PMX). Proses akan berhenti ketika kriteria pemberhentian telah dipenuhi yakni dengan menggunakan batasan maksimum iterasi.

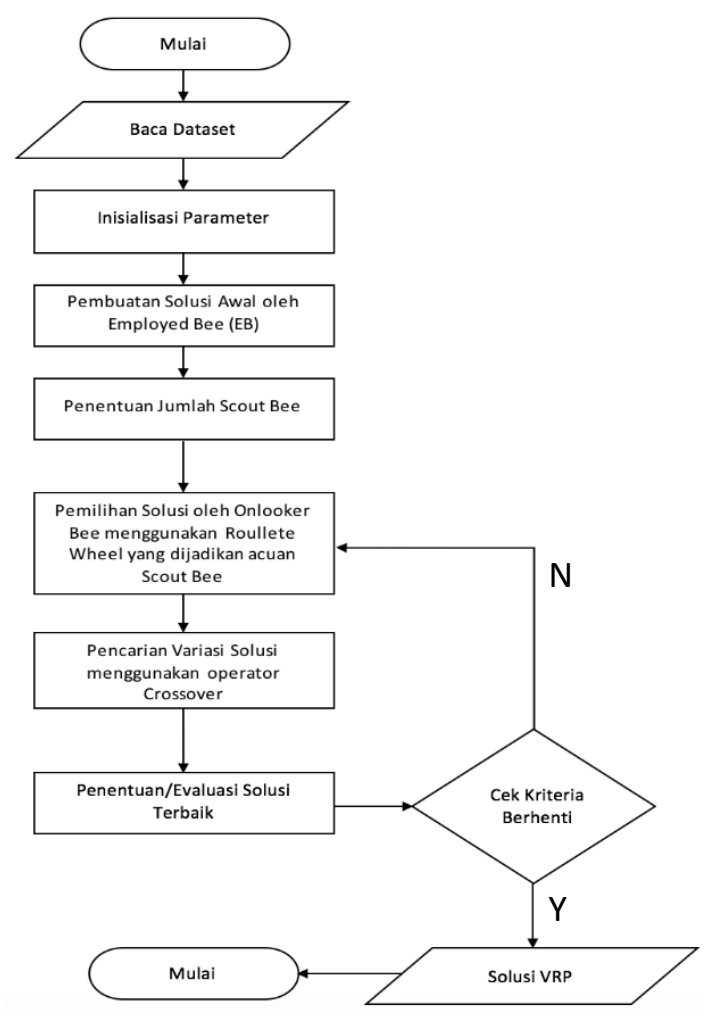

Gambar 2. Flowchart Pencarian Solusi Terbaik dengan HCABC 


\section{HASIL DAN PEMBAHASAN}

Pengujian dilakukan untuk melihat bagaimana performa dari dua metode crossover yang digunakan untuk merubah karakteristik dari koloni lebah scout. Dari pengujian yang telah dilakukan didapatkan hasil bahwa metode CX memiliki performa yang lebih unggul dibandingkan dengan metode PMX. Hal ini dapat dilihat dari hasil rute yang didapat $\mathrm{CX}$ lebih pendek di seluruh dataset yang diujikan. Pada Tabel 2 terlihat bahwa dari enam dataset yang diujikan, metode CX unggul di empat dataset dan memiliki performa yang sama dengan PMX pada dataset BN41K6 dan AN55K9. Jika dilihat dari hasil pengujian metode $\mathrm{ABC}$ sebelum dan setelah penerapan metode crossover, terdapat suatu hasil dimana penambahan metode crossover pada $\mathrm{ABC}$ ini lebih efektif ketika jumlah pelanggan/titik yang ada pada dataset relatif banyak. Hal ini dapat dilihat dari hasil pengujian yang menunjukkan keunggulan penerapan crossover ini pada dataset AN53K7 (52 pelanggan) dan AN55K9 (54 pelanggan), namun hal ini membutuhkan penelitian lanjutan untuk dapat menganalisa performa crossover untuk dataset-dataset pelanggan dengan jumlah titik yang lebih banyak lagi.

Tabel 2. Hasil Perbandingan Jarak

\begin{tabular}{|c|c|c|c|}
\hline \multirow{2}{*}{ Datase } & \multicolumn{3}{|c|}{ Distance } \\
\cline { 2 - 4 } & $\mathbf{A B C}$ & $\mathbf{C X}$ & PMX \\
\hline AN32K5 & 880 & 906 & 930 \\
\hline AN33K5 & 694 & 713 & 728 \\
\hline BN41K6 & 907 & 977 & 977 \\
\hline BN44K7 & 917 & 980 & 981 \\
\hline AN53K7 & 1244 & 1184 & 1199 \\
\hline AN55K9 & 1228 & 1162 & 1162 \\
\hline
\end{tabular}

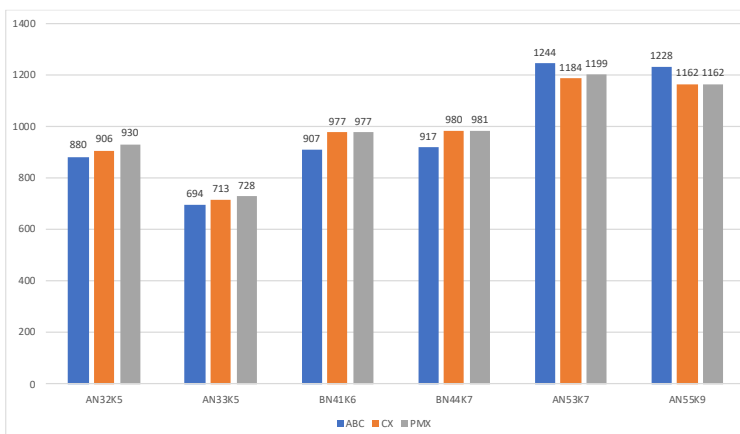

Gambar 3. Grafik Hasil Perbandingan Jarak

Dari sisi waktu yang diperlukan untuk menghasilkan solusi, CX juga memiliki waktu lebih singkat dalam menghasilkan sebuah solusi optimum. Pada Tabel 3 dapat dilihat performa waktu CX mengungguli dua metode lainnya. PMX memiliki performa waktu yang paling buruk performa PMX ini sangat dipengaruhi oleh jumlah pelanggan/titik dalam dataset dimana semakin banyak pelanggan maka waktu yang dibutuhkan akan semakin besar.

Tabel 3. Hasil Perbandingan Waktu Proses

\begin{tabular}{|c|c|c|c|}
\hline \multirow{2}{*}{ Datase } & \multicolumn{3}{|c|}{ Waktu Proses } \\
\cline { 2 - 4 } & ABC & CX & PMX \\
\hline AN32K5 & 4.323 & 3.033 & 5.246 \\
\hline AN33K5 & 4.456 & 3.235 & 5.399 \\
\hline BN41K6 & 3.543 & 1.626 & 6.163 \\
\hline BN44K7 & 3.657 & 2.022 & 9.595 \\
\hline AN53K7 & 5.432 & 4.995 & 7.892 \\
\hline AN55K9 & 5.132 & 3.420 & 12.282 \\
\hline
\end{tabular}




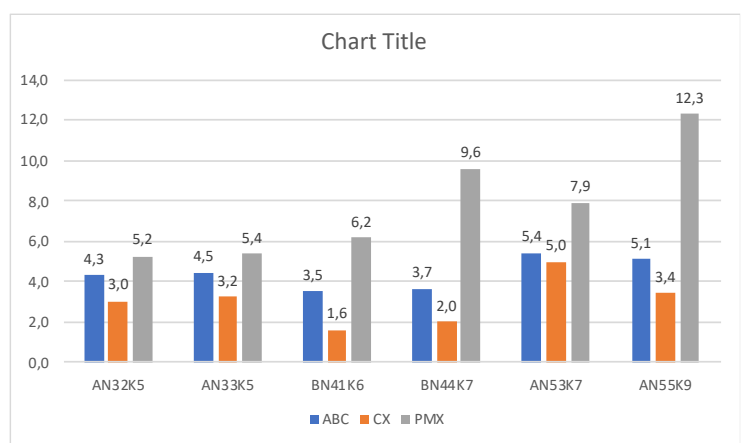

Gambar 4. Grafik Hasil Perbandingan Waktu Proses

Program aplikasi terkait penelitian ini juga telah berhasil dibangun untuk dapat menggambarkan solusi yang dihasilkan metode. Dalam aplikasi, pelanggan digambarkan dalam simbol titik-titik dan hubungan atau jalan dari pelanggan satu ke pelanggan lainya digambarkan melalui garis dengan warna yang berbeda-beda. Di sisi kanan aplikasi ditampilkan sebuah legend yang menunjukkan urutan mobil dalam pengiriman barang. Salah satu contoh tampilan aplikasi solusi ABC dengan penerapan CX untuk menyelesaikan permasalahan AN55K9 dapat dilihat pada Gambar 5.

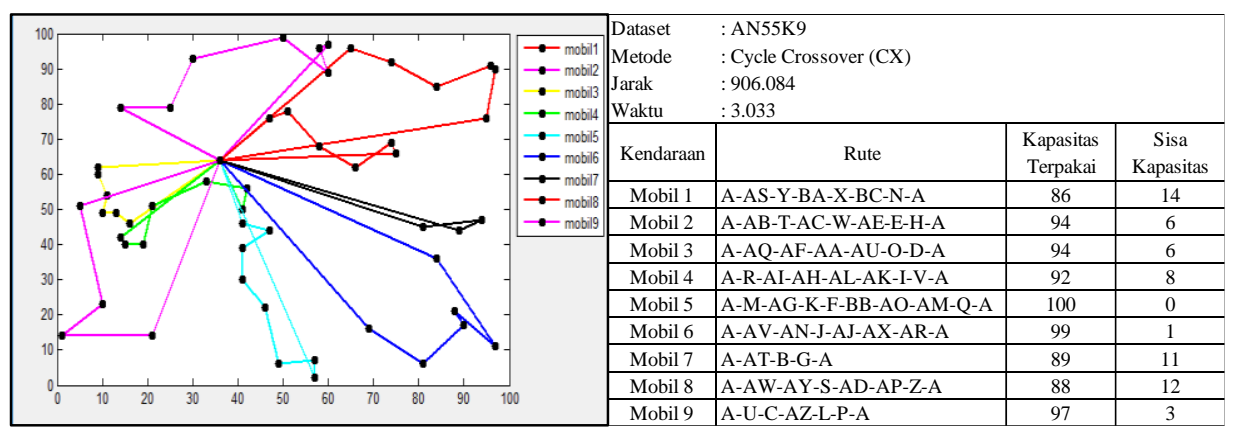

Gambar 5. Interface Aplikasi

\section{SIMPULAN}

Penelitian ini telah berhasil membangun aplikasi dalam Vehicle Routing Problem dengan penerapan metode Crossover dalam Artificial Bee Colony. Cycle Crossover (CX) memiliki kinerja yang lebih baik daripada Partially Mapped Crossover (PMX), hal ini terlihat dari solusi CX yang dihasilkan untuk semua dataset lebih baik atau sama dengan PMX. Selain memiliki kinerja yang lebih baik dalam hal jarak, CX juga memiliki kinerja waktu yang lebih cepat daripada PMX Jika dibandingkan dengan metode $\mathrm{ABC}$ sebelum penerapan crossover, ada beberapa dataset VRP di mana aplikasi Crosover dapat mengungguli $\mathrm{ABC}$, disamping itu terdapat suatu hasil dimana penambahan metode crossover pada $\mathrm{ABC}$ ini lebih efektif ketika jumlah pelanggan/titik yang ada pada dataset relatif banyak. Dalam hal waktu eksekusi CX lebih efisien bila dibandingkan dengan waktu eksekusi ABC.

\section{DAFTAR PUSTAKA}

[1] Lysgaard, J., L. A., \& E. R. (2004). A new branch-and-cut algorithm for the capacitated vehicle routing problem. Math. Program., Ser. A 100, 423-445

[2] Puljic Krunoslav, Manger Robert. (2013). Comparison of eight evolutionary crossover operators for the vehicle routing problem, MATHEMATICAL COMMUNICATIONS Department of Mathematics, University of Osijek, 359-375

[3] S. Kumar and R. Panneerselvam. (2012). "A Survey on the Vehicle Routing Problem and Its Variants," Intelligent Information Management, Vol. 4 No. 3, 66-74 
57 Jurnal Teknologi Informasi dan Komputer, Volume 5, Nomor 1, Januari 2019

[4] Sabet, S., Shokouhifar, M., \& Farokhi, F. (2016). A COMPARISON

BETWEEN SWARM

INTELLIGENCE. Electrical \&

Computer Engineering: An Amri, F., E.

B., \& M. F. (2012). Artificial Bee

Colony Algorithm untuk Menyelesaikan

Travelling Salesman Problem.

JURNAL DUNIA TEKNOLOGI INFORMASI Vol. 1, No. 1, 8-13.

[5] Zakaria N. Alqattan and Rosni Abdullah (2015), A hybrid artificial bee colony algorithm for numerical function optimization, International Journal of Modern Physics, vol 26. 